\title{
ARE COMFORT PREDICTIONS FROM ISO 2631-1 AND SELF-REPORTED COMFORT VALUES DURING OCCUPATIONAL EXPOSURE TO WHOLE- BODY VEHICULAR VIBRATION RELATED?
}

\author{
Katherine Plewa ${ }^{1}$, James P. Dickey ${ }^{1 *}$, Tammy Eger ${ }^{2}$, Michele Oliver ${ }^{3}$ \\ 1. University of Western Ontario, London Ontario, Canada \\ 2. Laurentian University, Sudbury, Ontario, Canada \\ 3. University of Guelph. Guelph, Ontario, Canada
}

\section{Introduction}

Exposure to whole-body vibration is strongly associated with health and comfort problems. The way in which workplace vibration exposure affects comfort is an important factor in worker activity levels and performance. International standards (ISO 2631-1) predict comfort based on vibration magnitudes, frequencies and durations. The objective of this study was to determine whether the ISO 2631-1 prediction method produces similar results to self-reported field comfort levels during occupational exposure to whole-body vehicular vibration.

\section{Methods}

6 degree of freedom seatpan acceleration data were recorded in various industrial machines in forestry ${ }^{2}$, mining ${ }^{4}$, and construction ${ }^{1}$ industries. Following an audio tone at 5-minute intervals, operators reported their comfort level on a ten point scale $^{3}$ based on the preceding minute of vibration exposure.

The one minute profiles of raw acceleration data were processed using the appropriate filtering and multiplying factors ${ }^{5}$. Frequency weighted RMS accelerations and point vibration total values were then calculated for each axis and combined as a vector sum. Comfort was predicted from the overall vibration total value for each acceleration profile. Overall vibration total, normalized overall vibration total, and total vibration dose values were compared to self-reported comfort for each of the three industries.

\section{Results}

We collected 45 matched sets of comfort and vibration data from 10 mining LHD vehicles, 18 sets of data from 6 forestry skidders and 60 sets of data from 15 construction scrapers. Each industry showed consistent trends for each predicted value; however, there were different relationships between the industries (Figure 1). The data from the construction industry showed weak positive relationships between predicted and self-reported comfort values, whereas the data for the forestry and mining industries showed no relationship or a weak negative relationship between predicted and self-reported comfort. 


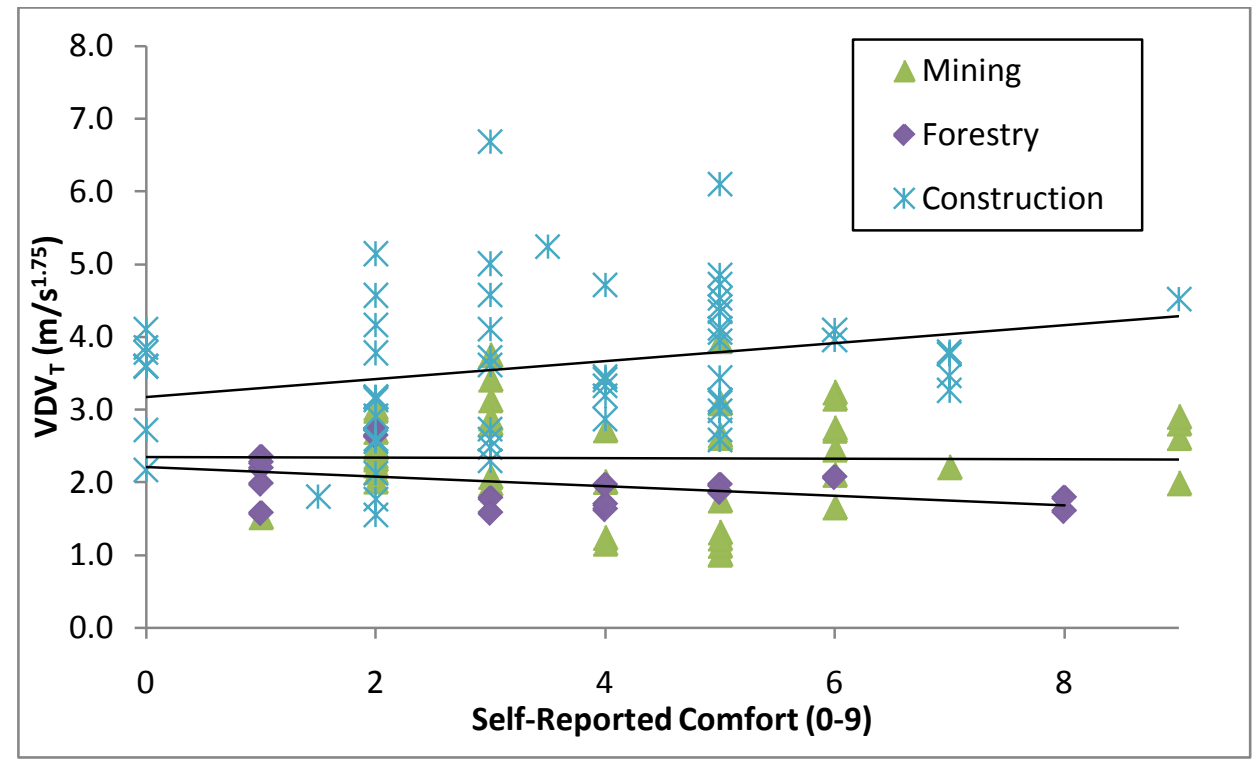

Figure 1. Total Vibration Dose Value $\left(\mathrm{VDV}_{\mathrm{T}}\right)$ versus Self-Reported Comfort for vehicles in the mining, construction and forestry industries.

\section{Discussion}

It is difficult to capture the relationship between comfort and vibration using mathematical equations because comfort is a subjective reflection of many factors. The predicted comfort levels did not accurately represent self-reported comfort. This may be due to limitations of the prediction equations or perhaps that the operators were incorporating additional factors such as temperature, noise and fatigue into their self-reported comfort ratings. In order to improve our understanding of the relationship between multi-axis vibration and comfort, a more controlled study should be done in the laboratory where workplace vibrations are simulated and subjects rate their comfort given a certain acceleration profile.

\section{References}

1. Cann, A.P., Salmoni, A.W., Vi, P., \& Eger, T.R. 2003. An exploratory study of whole-body vibration exposure and dose while operating heavy equipment in the construction industry. Applied Occupational and Environmental Hygiene, 18, (12) 999-1005.

2. Cation, S., Jack, R., Oliver, M., Dickey, J.P., \& Lee Shee, N.M. 2008. Six degree of freedom whole-body vibration during forestry skidder operations. International Journal of Industrial Ergonomics, 38, (9-10) 739-757

3. Dickey, J.P., Eger, T.R., Oliver, M.L., Boileau, P.E., Trick, L.M., \& Edwards, A.M. 2007. Multiaxis sinusoidal whole-body vibrations: Part II - Relationship between Vibration Total Value and discomfort varies between vibration axes. Journal of Low Frequency Noise Vibration and Active Control, 26, (3) 195-204

4. Eger, T., Stevenson, J., Boileau, P.E., \& Salmoni, A. 2008. Predictions of health risks associated with the operation of load-haul-dump mining vehicles: Part 1 - Analysis of whole-body vibration exposure using ISO 2631-1 and ISO-2631-5 standards. International Journal of Industrial Ergonomics, 38, (9-10) 726-738

5. ISO 2631/1 1997, Mechanical vibration and shock - Evaluation of human exposure to whole-body vibration - Part 1: General requirements, International Standards Organization, Geneva, Switzerland. 